DOI:

\title{
Improving the Satellite Power Supply Continuity Using Flywheel Energy Storage System
}

\author{
Mohamed El Amir Attalla ${ }^{1}$, and Hassna M. El Arwash ${ }^{2 *}$ \\ ${ }^{1}$ Department of Electronics and Communications Eng., Alexandria higher Institute of \\ Engineering \& Technology (AIET), Alexandria, Egypt. \\ ${ }^{2}$ Department of Mechatronics Eng., Alexandria higher Institute of Engineering \& Technology \\ (AIET), Alexandria, Egypt. \\ (Corresponding author: hasnaa.mohamed@aiet.edu.eg)
}

\begin{abstract}
Recently, Flywheel Energy Storage (FES) systems are gaining significant interest from National Aeronautics and Space Administration Glenn Research Center (NASA's GRC) in satellite applications due to their numerous advantages as an energy storage solution over the rest of the alternatives. Regarding FESS features such as high cycle life, long service life, high efficiency, high energy density and low environmental impact, this paper introduces a FESS management controller for use with the solar PV system in an integrated manner that ensures the continuity of the satellite power system and, thus, increases its efficiency. In addition, a prototype of the management control under various operating modes of the proposed unit is established. The satellite power supply management controller was implemented practically as a model using the Arduino controller. The practical results proved the continuity of the satellite operation in different operating modes using the FES system, which in turn would lead to improving the efficiency of the satellite feeding source compared to its performance using solar PV system only.
\end{abstract}

Keywords: Flywheel; satellite power supply; solar PV system.

\section{Introduction}

Currently, the operation of the International Space Station (ISS) is accomplished using several solar arrays, which are made up of several solar cells, or photovoltaic. It is expected in the coming years that more arrays will be added as space stations continue to be built. The idea of photovoltaic is based on the production of an electric current from sunlight after directing the cells towards the sun to capture as much light as possible. During daylight, the solar cells operate the vehicle directly and, at the same time, the energy storage unit, represented by nickel and hydrogen, is charged. The batteries are characterized by their ability to be recharged in order to provide the necessary energy for the station when the station is in the shade. The station is located in low Earth orbit, which leads to an increase in the duration of the station in the shade for up to 36 minutes from its 92 minute orbit. Therefore, these batteries are continuously discharged and recharged.[1]

Although electrochemical batteries are a source of energy storage for the station when it enters Earth's shadow in every orbit, NASA is focusing its research on an improved way to store electricity on spacecraft.
Due to many important disadvantages of electrochemical batteries, such as rechargeable nickel and hydrogen batteries, they have a limited number of discharging and recharging cycles, which forces the worn out batteries to be replaced in the space shuttle. This represents an expensive process in terms of the actual cost of the batteries, the lost charge space and at the time of installation [2].

Recently, flywheels have been on the list of storage technologies in electrical energy storage applications due to their advantages such as high energy efficiency, high energy and high energy density. Moreover, the most important parameters of FESS for satellite applications are efficiency, lifetime, reliability, operating temperature, weight, volume, and system cost. Additionally, flywheel systems perform the same function as rechargeable electrochemical batteries, in addition to their recent better performance in many ways [3] .

Over the past ten years, numerous developments have taken place in the flywheels in terms of materials with which they can be built [3, 4] and the method for controlling their performance, which has increased their capabilities [5- 8], while others 


\section{Mohamed El Amir Attalla, and Hassna M. El Arwas "Improving the Satellite Power Supply Continuity using Flywheel Energy Storage System"}

concentrated on the flywheel sizing and its different applications $[9,10]$. Therefore, the flywheel storage capacity is higher than the past. This means that the energy that can be stored in the flywheel, i.e., its kinetic energy, is much greater than the energy stored in an electrochemical battery on a mass basis.

A lot of studies and researches have been done and prepared to develop the FESS so that it can be used in many applications, and this was studied through three directions. The first one is through the internal development of the flywheel system in order to improve performance and reduce size for ease of use, but this direction experienced many difficulties. The second direction dealt with the development through the control system in the flywheel, but the limitations of this direction appeared in many applications. The third direction was focused on the adaptation of the application depending on the type of the application.

Regarding flywheel interior design development, a comparison of energy storage technologies have been performed in 2011 [3] by R. Peña-Alzola et al. The numerical and graphical review illustrated the different improvements and issues associated with FESS interior design. In 2011, a design was presented to build a long-lifetime flywheel with minor maintenance need for high energy density, supported by radial and axial magnetic bearings of low energy consumption. Thus, the energy-saving magnetic bearings flywheel is developed and verified via simulation and experimental investigations [4]. Also, in 2013, a flywheel associated with a gridconnected variable-speed wind generation scheme, using a Doubly-Fed Induction Generator (DFIG), has been investigated [5]. Consequently, the dynamic behavior of a wind generator, including models of the wind turbine, DFIG, matrix converter, converter control and power control, has been studied. Moreover, the control method of the flywheel energy storage system has been investigated with a classical squirrel-cage Induction Machine (IM) associated with a variable speed wind generation using cascade rectifier filter. Jiqiang Tang et al., introduced in 2018 a rotor's suspension stability control system.[6]

Other researchers focused on the Flywheel interior control system to sustain its effectiveness during operation. In 2013, Chi Zhang et al. have developed a mathematical model of flywheel's force and torque $[7,8]$. Based on PID controller, the control systems of the flywheel position and velocity have been designed. The proposed flywheel speed control systems were experimentally carried out and tested to prove the feasibility and correctness of the mathematical analysis of the proposed model. The proposed method, entitled "Cross Feedback Control (CFC)", was studied to ensure that the rotor's suspension is stable due to the whirling. A CFC method, with pre-modulated gains, proved its effectiveness and sustained the suspension stability under a wider range of speeds. Also, an optimal nonlinear controller was proposed in 2019 [9] based on Model Predictive Control (MPC) for a flywheel energy storage system in which the constraints on the system states and actuators were taken into account. Tube-based MPC was utilized as a robust controller to control the system modeling uncertainties and the external disturbances effect. The proposed method merits in controlling the dc link voltage and the flywheel speed response were demonstrated via simulation results. Up till now, the improvement of the internal flywheel design is still under study.

On the other hand, the application of flywheel in an integrated manner with other energy storage systems has been discussed in several researches. In 2013, the authors designed two energy storage systems based on chemical batteries and flywheel to optimize the energy requirement of typical Low Earth Orbit (LEO) satellites [10]. In addition, a comparison between the two systems was investigated considering their efficiency, reliability, weight, operational temperature and self-discharge dissipation to conclude the recommendations about their use in terms of their capability. Moreover, T. Elsayed et al., 2016, designed a controller to regulate the charging rate through controlling the flywheel terminal voltage [11]. Two modes of operations have been studied in this research, i.e., charging and discharging modes. In the charging mode, the converter operates in the buck mode, while it operates in the boost mode in the discharging mode. A current controller takes over the control of the injected current from the machine to the DC bus .

The researchers assert that the energy capacity stored per unit mass in a flywheel system is much greater than that in electrochemical batteries, and flywheels can be discharged at a higher rate as well, which means more available stored energy. It is also found that up to $80 \%$ more energy could be recovered from flywheels compared to electrochemical batteries under the same conditions. The depth of discharge adds several advantages to the flywheel. In terms of weight, flywheel systems are lighter than electrochemical batteries for the same storage capacity, which is one of the most important advantages, especially in applications where weight is a limiting factor such as spacecraft. In terms of increasing the charging and discharging cycles, the flywheel can also withstand more cycles, while reducing wear and tear on the system results in extended life. While the life of the electrochemical battery is between four and five years in the 
international space station (ISS), the flywheel lasts between 15 and 20 years. Each ISS module has a planned lifetime of 10 years [12].

This article proposes a management unit for controlling the power supply feeding the satellite subsystems in the presence of a flywheel, batteries, and solar cells to ensure the continuity feeding for the subsystems that operate incessantly and reliably leading to higher efficiency of the satellites. Therefore, the use of the flywheel as a source of energy storage for satellites enables them to fly in LEO and Geosynchronous Equatorial Orbit (GEO) orbits. Moreover, it presents the continuity and reliability and how the proposed management control unit increases the satellite's efficiency under different modes of operations. A prototype system is implemented for realistic results and conclusions. Extensive simulation results are introduced to compare the behavior of satellite power supply with and without Flywheel to investigate the high accuracy of the introduced approach.

\section{Aim and Research Significance}

Flywheel Energy Storage System (FESS)

Flywheel energy storage (FES) systems are featured by their long lifetimes with maintenance free compared to other storage methods, environmentally friendly electricity storage technology that can replace lead-acid batteries. When the stored energy had recovered from the system, the flywheel rotation speed decreased due to the principle of energy conservation. Adding energy to the system, in turn, increases the flywheel speed.

\section{Flywheel Description}

A flywheel is a rapidly rotating cylinder or disc suspended in an airtight container that stores electrical energy. The new generation of FES satellite systems consists of a flywheel supported by rollingelement magnetic bearing connected to a motorgenerator enclosed in a vacuum chamber. The importance of the magnetic bearing is to reduce friction and energy loss. However, the rotor is made of high-strength carbon fiber composites that have a higher tensile strength and can store much more energy for the same mass, while spinning at speeds of up to $50,000 \mathrm{rpm}$ in a vacuum container. Moreover, the flywheel can reach its capacity in a matter of minutes [11, 13]. Due to their low weight, high energy density, high efficiency, high reliability and high speed, Brushless DC (BLDC) motors are the most common type used in FESS. Figure 1 shows the main components of the FES satellite as approved by NASA.

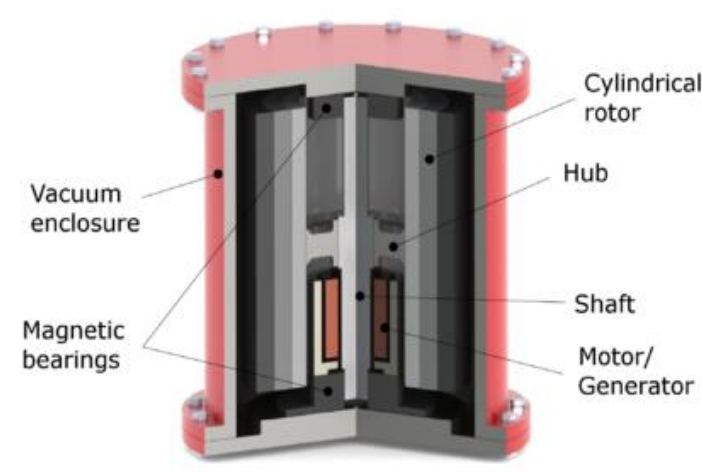

Fig. 1: The main components of the satellite FESS

\section{Form of energy storage} as approved by NASA

Flywheel is considered one of the most commonlyused energy storage systems all over the world. In this section the form of energy storage inside the flywheel will be explained briefly. As mentioned in [14], the flywheel moment of inertia is calculated using Eq. (1) depending on different cylinder shapes. The angular velocity and stored rotational energy are calculated using Equations (2) and (3), respectively.

Moment of inertia: $J_{m}=\int_{m=\text { mass of sphere }} r^{2} d m$

Angular velocity: $\omega_{m}=2 \pi \cdot n_{m}$

Stored rotational energy: $W_{k i n}=\frac{1}{2} J_{m} \omega^{2}$

where:

$m:$ is the integral of the flywheel's mass, and

$n_{m}$ : is the rotational speed (number of revolutions per second).

\section{Specific energy}

The maximal specific energy of a flywheel rotor is mainly dependent on two factors: the first is the rotor's geometry and the second is the properties $\sigma$ and $\rho$ ) of the material being used. For a singlematerial, isotropic rotors, this relationship can be expressed by Eq. (4) as mentioned in [11].

$$
\frac{E}{m}=K\left(\frac{\sigma}{\rho}\right)
$$

where:

$E$ : is kinetic energy of the rotor $[\mathrm{J}]$,

$m:$ is the rotor's mass $[\mathrm{kg}]$,

$K:$ is the rotor's geometric shape factor [dimensionless], $\sigma$ : is the tensile strength of the material $[\mathrm{Pa}]$, and

$\rho:$ is the material's density $\left[\mathrm{kg} / \mathrm{m}^{3}\right]$.

In the following, the two main factors affecting the maximum specific power of the flywheel rotor will 


\section{Mohamed El Amir Attalla, and Hassna M. El Arwas "Improving the Satellite Power Supply Continuity using Flywheel Energy Storage System"}

be discussed briefly.

\section{The geometry of the rotor (shape factor)}

The highest possible value for the shape factor of a flywheel rotor, is $\mathrm{K}=1$, which can be achieved only by the theoretical constant-stress disc geometry [14]. A constant-thickness disc geometry has a shape factor of $K=0.606$, while the value is $K=0.333$ for a rod of constant thickness. A thin cylinder has a shape factor of $K=0.5$. For most flywheels with a shaft, the shape factor is below or about $K=0.333$. A shaft-less design [14] has a shape factor similar to a constant-thickness disc $(K=0.6)$, which enables a doubled energy density.

\section{Characteristics of the substance used}

For energy storage, materials with high strength and low density are desirable. For this reason, composite materials are frequently used in advanced flywheels. The strength-to-density ratio of a material can be expressed in $\mathrm{Wh} / \mathrm{kg}$ (or $\mathrm{Nm} / \mathrm{kg}$ ), where values greater than $400 \mathrm{Wh} / \mathrm{kg}$ can be achieved by certain composite materials [14].

\section{r System DescriptionSatellite Powe}

Solar photovoltaic installation usually requires a solar cell array, energy storage device, maximum power tracker (MPPT), and DC-to-DC converter. The MPPT is very important to extracts the maximum available power under various conditions of solar array. In the following subsections, a highlight will be spotted about the main satellite power system components.

\section{Solar arrays}

In satellite application, to have a peak generated power during daylight, it is obligatory to design the solar array using the following steps [15]:

1. Selection of the solar cells type;

2. Determining the solar array power capability;

3. Estimating the output power per unit area of the solar array;

4. Estimating the required output power at the Beginning Of Life (BOL) of the satellite;

5. Estimating the output power at the satellite End Of Life (EOL).

In the following, a brief discussion about each step will be demonstrated:

\section{Selection of the solar cells type:}

The most important parameters in solar cells for satellites applications are efficiency and lifetime. Triple junction 3J (GaInP/GaInAs/Ge) cells are recommended for both small and LEO satellites since they have higher efficiency than GaAs cells [16]. Although the cost of the $3 \mathrm{~J}$ cells is higher than GaAs, they are smaller and lighter compared to GaAs cells. This presents big funds for the launching costs, while satisfying the same power capability of the larger and heavier GaAs arrays.

\section{Determining the solar array power capability:}

The total extent of the generated power, which can be achieved by the solar array during the non-shadowing periods, is determined by summing the power requirements of the spacecraft subsystems during daylight and the needed power to charge the secondary batteries to fulfill the eclipse power demands. The solar array generated power $P_{s a}$ can be expressed as, [17].

$P_{s a}=\frac{\frac{P_{e} T_{e}}{X_{e}}+\frac{P_{d} T_{d}}{X_{d}}}{T_{d}}=9.34 \mathrm{~kW}$

where:

$P_{e}, P_{d} \quad:$ are the spacecraft power requirements during eclipse and daylight, respectively,

$T_{e}, T_{d} \quad:$ are the eclipse and the daylight durations for the satellite in its orbit, respectively,

$X_{d}, X_{e} \quad$ : are the efficiency of the spacecraft power subsystem to supply the power from the array to the loads in daylight and to the batteries for charging during daylight, respectively.

Estimating the output power per unit area of the solar array:

The output power per unit area $\left(P_{o}\right)$ can be calculated by multiplying the efficiency of the PV material $(\eta)$ by the solar irradiance intensity $\left(G_{s c}\right)$ [17]. Since the $3 \mathrm{~J}$ cells power efficiency is $30.7 \%$ and using solar irradiance intensity $G_{s c}=1321 \mathrm{w} / \mathrm{m}^{2}$ And $P_{o}$ can be calculated using equations (6), (7), respectively.

$$
G_{s c}=G_{s c o}\left(1+0.033 \cos \frac{360 d}{365}\right) \mathrm{kw} / \mathrm{m}^{2}
$$

$$
P_{o}=\text { solar irradiance intensity } \times \eta=405.547 \mathrm{~W} / \mathrm{m}^{2}
$$

Estimating the required output power at the beginning of life (BOL) of the satellite

The required power at the beginning of life is given by:

$$
P_{\text {Bol }}=P_{o} I_{d} \cos \theta=312.27 \quad \text { Watt } \quad(8
$$

where $\theta$ is the incidence angle between the vector 
normal to the solar arrays and the direction of the sun line $\left(\theta=23.5^{\circ}\right.$ in worst case) [17]. In the presented design, $\theta$ equals 0 since the satellite uses a power tracking mechanism.

Estimating the output power at the satellite end of life (EOL):

The power degradation factor $\left(L_{d}\right)$ through the satellite lifetime is calculated as:

$L_{d}(1-\text { degradation per year })^{\text {satellite life }}=0.9$

As mention before, the degradation per year for $3 \mathrm{~J}$ solar cell is $0.5 \%$. Therefore, the output power at the satellite EOL can be estimated as:

$P_{\text {Eol }}=P_{\text {Bol }} \times L_{d}=281.043 \mathrm{Watt}$

By comparing the performance of solar panels that use 3J solar cells with panels that use GaAs solar cells, it is found that the performance of the manufactured cells of the first type is much better than the second type, due to the $3 \mathrm{~J}$ cells higher efficiency. Figure 3 illustrates the degradation in the output power delivered to the power subsystem over the life of the satellite using the cell types $3 \mathrm{~J}$ and GaAs. It can be noticed that, the degradation rate of $3 \mathrm{~J}$ cells is much lower than that of GaAs.

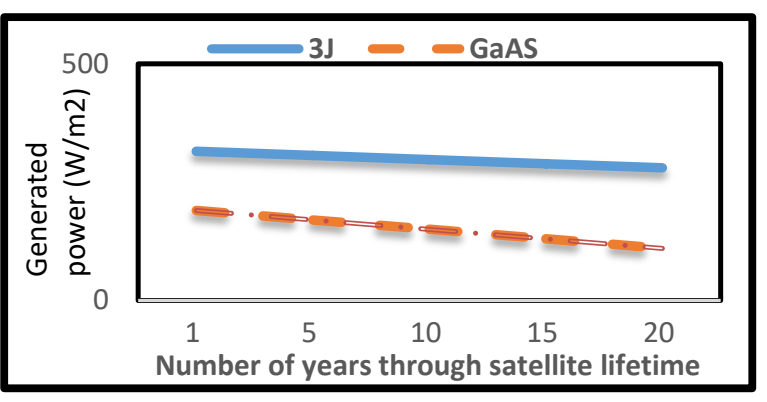

Fig. 3: Output power degradation over the satellite lifetime

\section{Battery Base Energy Storage System}

Two common types of batteries, which are used in space programs, are $\mathrm{Ni}-\mathrm{Cd}$ and $\mathrm{Ni}-\mathrm{H} 2$. In the following, Table (1) depicts the properties of these batteries [18].

Table 1: Properties of Ni-Cd and Ni-H2 batteries [18]

\begin{tabular}{lcc}
\hline \hline \multicolumn{1}{c}{ Battery Properties } & $\mathrm{Cd}-\mathrm{Ni}$ & H2-Ni \\
\hline (Wh/kg)Specific energy & 30 & 60 \\
(\%) Energy efficiency & 72 & 70 \\
((day/\% discharge-Self & 0.5 & 5 \\
$\left(\mathrm{C}^{\circ}\right)$ Temperature range & to $4015-$ & to $5020-$ \\
(V) geCell volta & 1.2 & 1.2 \\
Memory effect & Yes & Yes \\
\hline \hline
\end{tabular}

From Table (1), it can be demonstrated that Ni-Cd has a lower stored energy for the same weight. Although the self-discharge rate of $\mathrm{Ni}-\mathrm{H} 2$ is more than $\mathrm{Ni}-\mathrm{Cd}$, but in LEO satellites, charge and discharge duration is very short and, so, the effect of this parameter is negligible. Also, operational temperature range of $\mathrm{Ni}-\mathrm{H} 2$ (from -20 to $50{ }^{\circ} \mathrm{C}$ ) is more than $\mathrm{Ni}-\mathrm{Cd}$ (from -15 to $40^{\circ} \mathrm{C}$ ) [18]. Therefore, $\mathrm{Ni}-\mathrm{H} 2$ is more suitable for Chemical Battery Energy Storage System (CBESS) in this application.

The satellite sample power consumption is 40 watts for 30 minutes ( 20 watt hours) in the duration of the eclipse, and the maximum permissible depth of discharge for chemical batteries in LEO is $15 \%$ [19]. Therefore, the power capacity for batteries should be as follows:

Batteries Capacity $=\frac{20}{0.15} W h=133.33 W h$

\section{Model Approach of Satellite Power System}

\subsection{Satellite Power System without FESS}

Generally, load energy storage systems are connected through series and parallel structures. Parallel structure has greater overall efficiency [20]. Moreover, different topologies are used as DC-DC converter in satellite power transmission system. Each topology has its own advantages and disadvantages [21]. Bidirectional push-buck topology is the topology most suggested in previous studies. The efficiency of the CBESS power electronics based on this chassis is about $95 \%$.

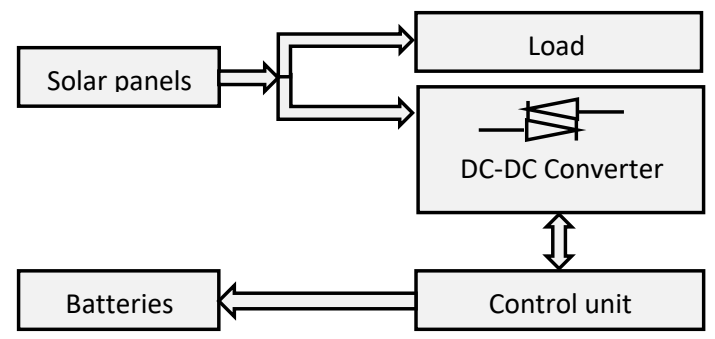

Fig. 4: Bidirectional boost-buck converter with parallel connection for a CBESS for satellite applications without FESS

Figure 4 shows the parallel structure of a DC-DC bi-directional converter for CBESS and the batteries are connected to the DC bus through a two-way DC-DC converter in a parallel manner.

For satellite, there are three modes of operation related to sunlight as shown in Fig. (5). In the following, a brief discussion about the three modes according to sunlight will be demonstrated . 


\section{Mohamed El Amir Attalla, and Hassna M. El Arwas "Improving the Satellite Power Supply Continuity using Flywheel Energy Storage System"}

First mode: when the satellite receives sunlight, it should control the DC bus voltage with respect to the maximum power point tracking (MPPT) operating condition of the solar panels. Also, the batteries should be charged according to the temperature and charging characteristics of the batteries.

- Second mode: when the batteries are charging, they can only provide lean charging and standby to the discharge state.

- Third mode: when the batteries are discharging, they cannot provide the necessary energy for the satellite in the eclipse period..

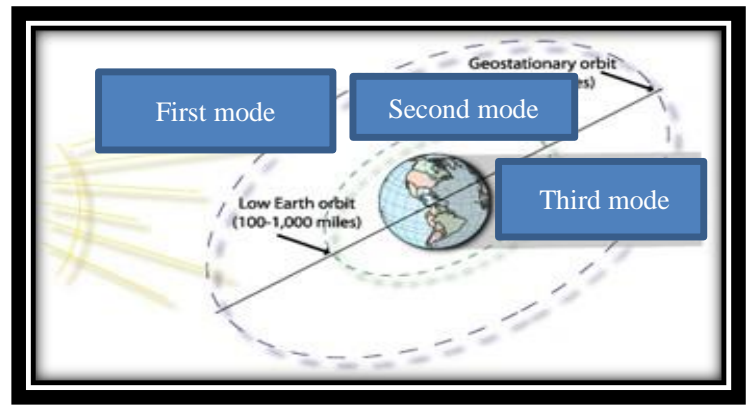

Fig. 5: The three modes of operation related to sunlight in LEO and GEO

As demonstrated from the applied experimental results of DC load capability of a satellite power system in the above three operating modes using only batteries without flywheel [19], in the following, a detailed explanation of each mode:

1. Charging Mode: It can be divided into three sections, namely the period from $6 \mathrm{AM}$ to 8 $\mathrm{AM}$, from $8 \mathrm{AM}$ to $10 \mathrm{AM}$ and the period from $10 \mathrm{AM}$ to $4 \mathrm{PM}$, the following is a presentation of the three main periods:

- From 6 AM to 8 AM: During this period, the solar cells system is exposed to sunlight, the batteries begin charging until they reach a value of 12 volts at $8 \mathrm{AM}$. Meanwhile, until the battery charge exceeds the voltage required to operate the sub-systems, which is 12 volts, the subsystems will be completely shut down.

- From 8 AM to 10 AM: During this period, the solar cells system is still exposed to sunlight, and the batteries are charged from 8 AM until they reach a value of 13 volts at $10 \mathrm{AM}$ and the subsystems are start operating.

- From $10 \mathrm{AM}$ to $4 \mathrm{AM}$ : the subsystems still obtaining their energy needs directly through the batteries, and this period is the peak operating period for the satellite sub-systems, in which the batteries appear in two cycles: charging from sunlight and discharging to meet the needs of the load (subsystems) at the same time.

2. Charging reduction Mode: It is the period from 4 PM to 8 PM, during this period, the sunlight is not focused on the solar arrays and still the sub-systems mainly depend on the batteries to meet its needs and there is no compensation for the batteries charge.

3. No charging Mode: This period from $8 \mathrm{PM}$ to $6 \mathrm{AM}$, during this long time, the satellite subsystems will be completely shut down which will affect their performance [19]. Therefore, it is necessary to provide an alternative energy storage system and this is what the study presents in this paper.

This sequence of satellite system operation repeats daily. Therefore, it is necessary to provide an alternative energy storage system and this is what the study presents in this paper.

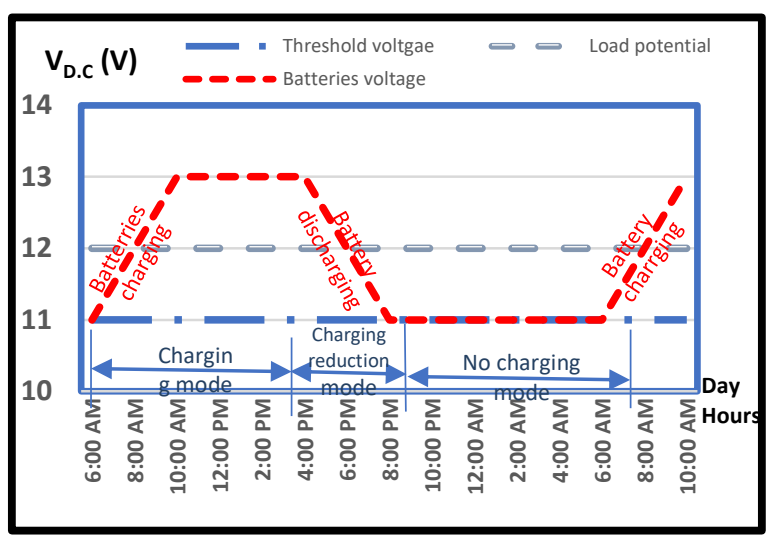

Fig. 6: DC load potential during batteries charging to discharging operation (without flywheel)

\subsection{Proposed Satellite Power System with FESS}

The main objective of this work is the electrical and electromechanical integration of flywheel with the solar PV system. The following subsections will discuss the sequence to accomplish the target.

\section{- Block Diagram Structure}

To achieve the goal, the photovoltaic system is used according to its integration to supply the satellite with the electrical power it needs by using $\mathrm{Ni}-\mathrm{H} 2$ batteries. Whereas, to achieve feeding continuity in cases of cloudy or low battery charge, the flywheel system, designed for the purposes of satellites, is used and to attain system voltage stabilization through FESS, there is a necessity to use voltage regulator. Figure (7) shows the arrangement of the proposed hybrid 
system to handle the energy management of satellite in sun light duration as well as eclipse.

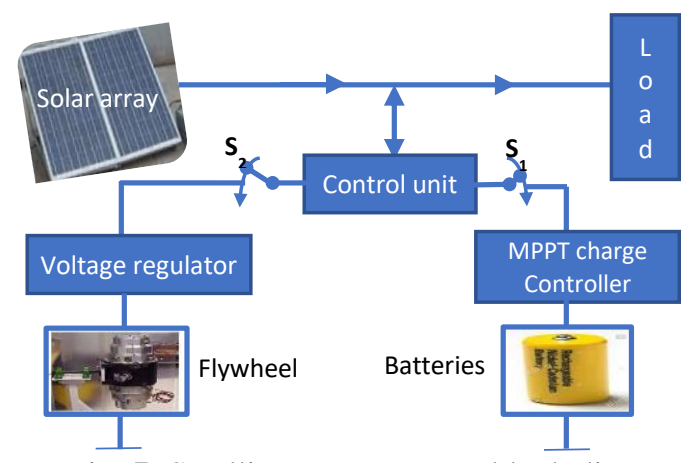

Fig. 7: Satellite power system block diagram

A satellite power system requires solar panels to provide energy and orientation as shown in Fig. (7) and Table (2). There are two regions in the orbital path of the satellite; the bright and dark region.

In the bright region, the control unit will compare the batteries voltage level then closing $S_{1}$ that yields the solar panels to charge the batteries through MPPT charge controller that sustains the load voltage level constant. At the same time, the satellite subsystems will get their power needs through the batteries system. In the contrary, the flywheel system will store the mechanical power via DC/DC converter.

In the dark region, the control unit will compare the batteries voltage level and once it has low level, $S_{1}$ will be opened and then $S_{2}$ will be closed to let flywheel energy storage system (FESS) to start feeding the satellite subsystems through a voltage regulator to sustain the required voltage level. Table 2 shows the satellite subsystems modeled as periodic tasks as mentioned in [22].

Table 2: satellite subsystems modeled as periodic tasks [22]

\begin{tabular}{|c|c|c|}
\hline $\operatorname{Task}_{\tau_{i}}$ & $\begin{array}{l}\text { Period } \\
p_{i}^{(\min )}\end{array}$ & $\begin{array}{c}\text { Maximum power } \\
\text { consumption }\left(l, v_{i}\right)(\mathrm{W})\end{array}$ \\
\hline$\tau_{1}$ Onboard computer: & 100 & 0.38 \\
\hline$\tau_{2}$ Receiver : & 100 & 0.15 \\
\hline$\tau_{3}:$ Magnetorquer & 10 & if $8.0 \leq 61.00 l^{9.0} \geq 10.0 \%$ \\
\hline$\tau_{4}$ Magnetometer : & 10 & if $0.0 \leq 60.23 l^{5.0} \geq 10.0 \%$ \\
\hline$\tau_{5}$ Transmitter : & 10 & $\begin{array}{c}\text { if } 4.0 \leq \cdot 1.11 l 4.0 \geq 10.0 \% \\
\left.+v_{\left(v_{4}\right.}=1,2,3, \text { or } 4\right)\end{array}$ \\
\hline$\tau_{6}$ Camera : & 10 & $\begin{array}{c}\text { if } 0.0 \leq \cdot 0.3 l \geq 10.0 \% \\
v\left(v_{5}=1,2,3, \text { or } 4\right)\end{array}$ \\
\hline
\end{tabular}

\section{The proposed satellite power system components}

Figure 8 demonstrates the applicable satellite power system using the two different types of energy storage systems; CBESS and FESS and their sequences. The main technical indicators for the used CBESS as demonstrated in Table (1) and FESS are illustrated in the appendix 1 as declared in [23].

\section{Control unit structure}

This main circuit is responsible for regulating and feeding the satellite and its payload by controlling the connection of the energy storage systems; chemical batteries (CBESS) or flywheel (FESS). The circuit consists of three main elements; voltage sensors, microcontroller and relay module as shown in Figs. (9) and (10). In the following, the three main elements will be discussed briefly .

\section{Voltage sensor}

To indicate the voltage level, each energy storage source is connected to a voltage sensor. The voltage sensor is a simple module that can be used with Arduino (or any other microcontroller with input tolerance of $5 \mathrm{~V}$ ) to measure external voltages that are greater than the maximum acceptable value .

\section{Microcontroller}

Microcontrollers are a compact computer manufactured to control the functionality of systems embedded in office equipment, robots, home appliances, cars, and a number of other gadgets. The microcontroller consists of several components such as: memory, peripherals and, most importantly, the processor. In this research, the Arduino Uno is used because it is an open source microcontroller board based on Microchip ATmega328P microcontroller and developed by Arduino.cc. The board is equipped with combinations of digital and analog input/output pins that can be connected to various expansion boards and other circuits. The microcontroller receives the voltage value from the voltage sensor and begins to select a suitable energy storage system. Through the Arduino, as an open source controller, the voltage value is received from the sensors and an action is taken with the relay unit and this data is monitored via the serial monitor.

\section{$\underline{\text { Relay module }}$}

The relay unit is the third stage in the control circuit that receives power and turns it off or on in the load circuit. The circuit contains two relay units responsible for connecting the power supply to the microcontroller circuit. There are two energy storage systems used in this application; chemical battery and 


\section{Mohamed El Amir Attalla, and Hassna M. El Arwas "Improving the Satellite Power Supply Continuity using Flywheel Energy Storage System"}

flywheel. Therefore, the relays will control their connection to the microcontroller on the basis of their voltage level, which should be more than 12 volts. To enable the microcontroller to operate safely, the relay units are connected with a reverse current blocking diode and a transistor is used to limit the current to avoid passing more than $40 \mathrm{~mA}$ to the microcontroller.

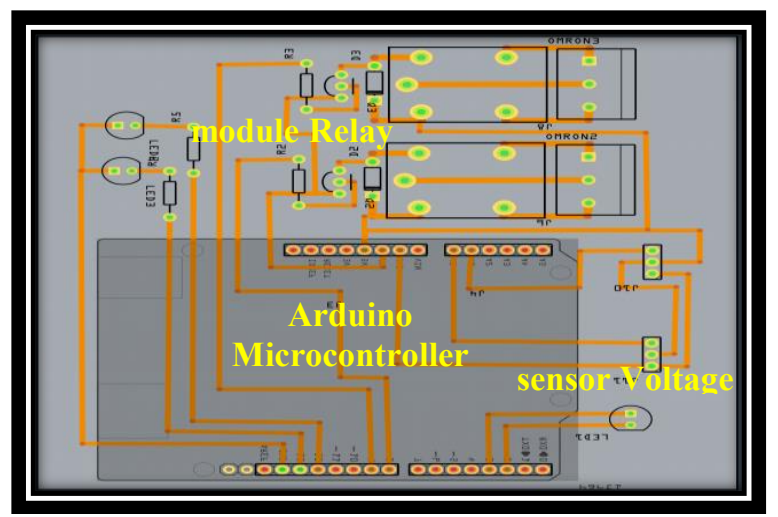

Fig. 9: Control unit schematic diagram

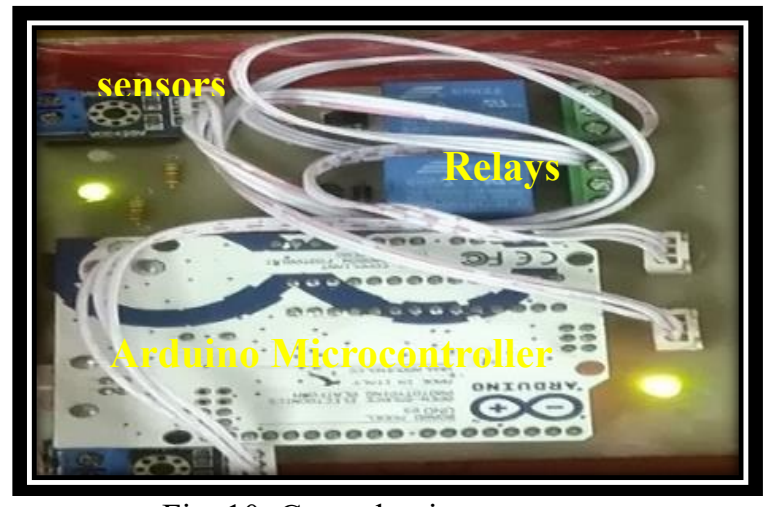

Fig. 10: Control unit prototype

\section{- Control unit operation}

The satellite power supply control unit is designed typically for three modes of operation based on the requirements of the energy storage sub-system of the satellite. The three modes of operation are:

1) Mode 1, 2) Mode 2, 3) Mode 3.

In the following, each mode will be discussed in detail. Moreover, a flowchart of the management control duty will be demonstrated as shown in Fig. (11).

1) Mode 1: this mode will be activated in sun light duration. In this mode, the solar array produces enough current to provide satellite subsystems current requirement and at the same time charges the flywheel. Moreover, batteries will be charging at a constant power through the MPPT charging controller and flywheel will charge at a constant DC voltage rate via a voltage regulator.

2) Mode 2: this mode will be activated in partial sun duration, in this mode, the solar array continues to provide satellite subsystems current but it cannot provide enough current to charge the batteries and, thus, battery voltage $\left(\mathrm{V}_{\mathrm{b}}\right)$ is equal to flywheel voltage $\left(\mathrm{V}_{\mathrm{f}}\right)$, with the priority is to the batteries. Otherwise, the DC bus voltage regulation function is transferred to the flywheel system.

3) Mode 3: this mode will be activated in the dark region, where the sun gets dark and $V_{f}>V_{b}$. The flywheel system provides all satellite subsystems current requirements and the voltage regulator will regulate the DC bus voltage.

\section{- Simulation results}

The search for high power transmission efficiency and long life are important goals when designing a power supply subsystem for satellite applications. To achieve these goals, power was supplied to a small satellite, where a flywheel energy storage system is used in an integrated manner with chemical batteries to sustain the continuity of satellite power supply.

The experimental results show batteries and flywheel operation for charging and discharging position during illumination and shading period as mentioned in Table (3). In the following, the advantages of the proposed control unit will be confirmed by the simulation results of the power supply system.

Table 3: Experimental results for bus voltage and storage status for satellite power system during different operating modes

\begin{tabular}{|c|c|c|c|}
\hline $\begin{array}{l}\text { Mode of } \\
\text { operation }\end{array}$ & Bus Voltage & $\begin{array}{l}\text { Batteries } \\
\text { status }\end{array}$ & $\begin{array}{l}\text { Flywheel } \\
\text { status }\end{array}$ \\
\hline Mode 1 & $\begin{array}{l}\text { Batteries voltage } V_{b} \\
\text { is regulated by solar } \\
\text { array system } \\
\left(\mathbf{V}_{\mathbf{f}}<\mathbf{V}_{\mathbf{b}}\right)\end{array}$ & $\mathrm{ON}$ & $\mathrm{OFF}$ \\
\hline Mode 2 & $\begin{array}{l}\text { Priority for } \\
\text { Batteries } \\
\left(\mathbf{V}_{\mathbf{f}}=\mathbf{V}_{\mathbf{b}}\right)\end{array}$ & $\mathrm{ON}$ & $\mathrm{ON}$ \\
\hline Mode 3 & $\begin{array}{l}\text { Flywheel voltage } \mathrm{V}_{\mathrm{f}} \\
\text { is regulated by } \\
\text { flywheel system } \\
\left(\mathbf{V}_{\mathbf{f}}>\mathbf{V}_{\mathbf{b}}\right)\end{array}$ & OFF & $\mathrm{ON}$ \\
\hline
\end{tabular}

Figure 12 shows the simulation results using an Arduino controller. The system is initially in the charging mode (Mode 1) with a battery voltage of 12 $\mathrm{V}$ charging $\left(\mathrm{V}_{\mathrm{b}}>\mathrm{V}_{\mathrm{f}}\right)$. So, the batteries will be $\mathrm{ON}$ as shown in Fig. (12-a). With time, the available voltage from batteries and DC bus is reduced and the voltage begins to decrease. The system becomes in the charging reduction mode (Mode 2) and the flywheel 
begins to regulate the DC bus voltage to 12 volts. The CBESS still provides sufficient current to meet the satellite subsystems, even at a slower rate, and the FESS is fully charged $\left(\mathrm{V}_{\mathrm{b}}=\mathrm{V}_{\mathrm{f}}\right)$ but the priority still for the CBESS as shown in Fig. (12-b). During the dark time; discharging mode (Mode 3), FESS still supplies enough power to feed the satellite subsystems,

$\left(\mathrm{V}_{\mathrm{f}}>\mathrm{V}_{\mathrm{b}}\right)$ and, then, the flywheel is $\mathrm{ON}$ as shown in Fig. (12-c). From the obtained simulation results, it can be seen that the experimental results shown in Table (3) have been confirmed, which indicates the success of the proposed management unit both practically and experimentally.

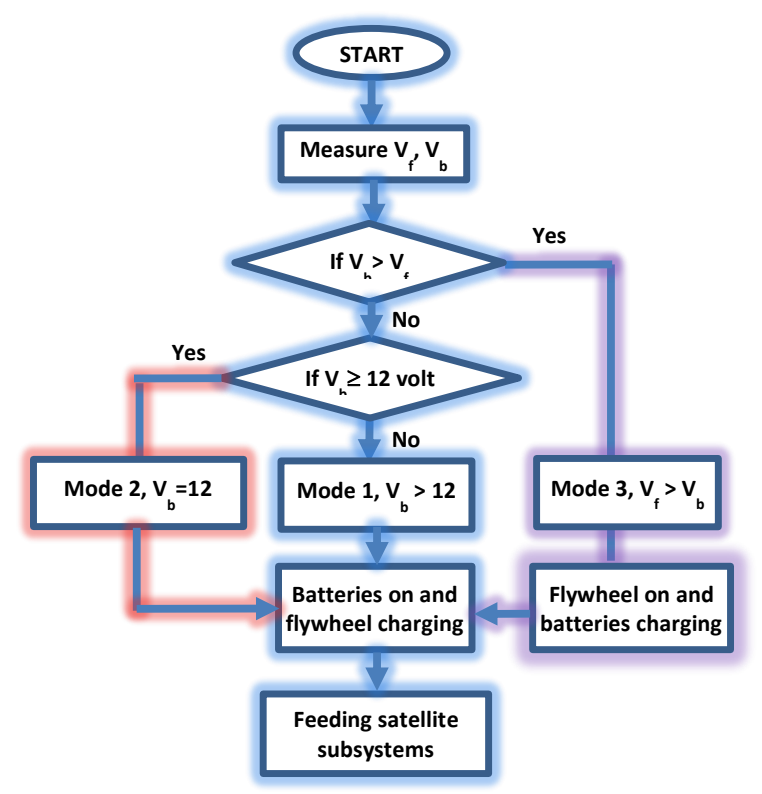

Fig. 11: The flowchart for satellite power system management control system

Figure 13 shows the relationship between the voltage of the batteries and the voltage of the satellite subsystems to be operated in the presence of the energy storage wheel throughout the day. We find that according to the procedures shown in the flow chart in Fig. (11), throughout the hours of the day the flywheel compensates for what falls short in feeding the batteries (from $8 \mathrm{PM}$ until $8 \mathrm{AM}$ ). In the following the operation of FESS will discuss as follows:

From 11 AM to 7 PM: during this time duration, flywheel is charging and the subsystems still feeding from the batteries.
- From 7 PM to 11 AM: during this time, the batteries is not satisfied feeding the satellite subsystems, so, the flywheel is discharging to compensate the drop of batteries, which continually feeds the satellite source. This allows the satellite to operate more efficiently.

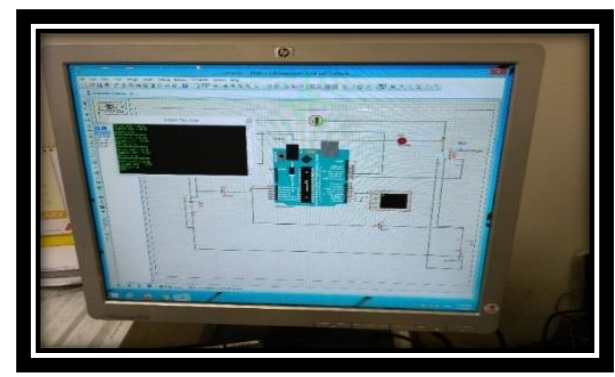

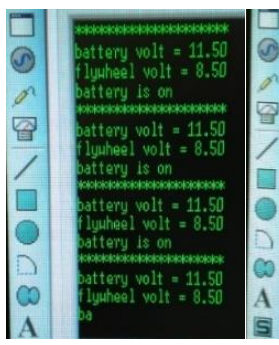

(a) Mode 1

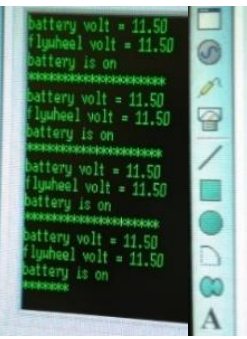

(b) Mode 2

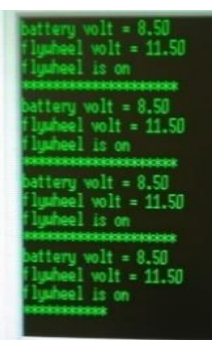

(c) Mode 3
Fig. 12: Modes of operation of the control unit

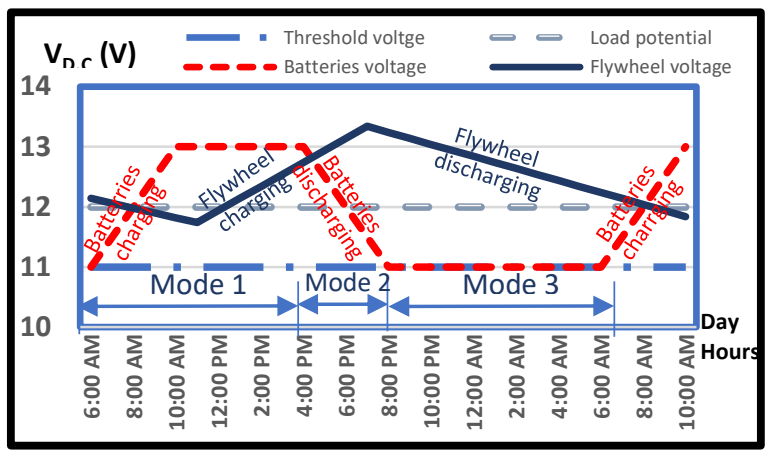

Fig. 13: DC load potential during batteries and flywheel charge to discharge operation

\section{Conclusions}

This paper has presented unit management control organization feeding satellite components and their continuity during charging and discharging modes of an energy system based on the integration between the solar system and the flywheel storage system. Also, the operating modes of the satellite are illustrated based on the status of solar PV with CBSS system and FESS, in order to overcome the shortcomings that occur during the period of discharged batteries and the inability to feed the 
components of the satellite. Experimental and simulation results show the success of the proposed prototype management control unit in different operating modes.

\section{References}

[1] Garcia, Mark . "International Space Station Overview". NASA. Retrieved 28 March 2021.

[2] Alexander A Voorhies 1, C Mark Ott 2, Satish Mehta 2, Duane L Pierson 2, Brian E Crucian 2, Alan Feiveson 2, Cherie M Oubre 2, Manolito Torralba 1, Kelvin Moncera 1, Yun Zhang 1, Eduardo Zurek 3, Hernan A Lorenzi 4 Study of the impact of long-duration space missions at the International Space Station on the astronaut microbiome 2019 Jul 9; 9(1): 9911 DOI: 10.1038/s41598-019-46303-8.

[3] R. Peña-Alzola, R. Sebastián, J. Quesada, and A. Colmenar, (2011), "Review of flywheel based energy storage systems“, In 2011 International Conference on Power Engineering, Energy and Electrical Drives, PowerEng, 2011 (1-6). IEEE., 10.1109/PowerEng.2011.6036455.

[4] Arkadiusz Mystkowski, Artur Rowinski (2011), "Construction And Control Of AMBs High Speed Flywheel", The archive of Mechanical Engineering, (2011), Vol. LVIII (1): 79-89, DOI: 10.2478/v10180-011-0005-7.

[5] Parfomak, P.W., "Energy Storage for Power Grids and Electric Transportation: A Technology Assessment; Congressional Research Services“, Washington, DC, USA, 2012.

[6] Jiqiang Tang*, Shaopu Zhao, Ying Wang, and Kuo Wang "High-speed Rotor's Mechanical Design and Stable Suspension Based on Inertiaratio for Gyroscopic Effect Suppression" International Journal of Control, Automation and Systems, Vol. 16 (4), (2018) 1577-1591 http://dx.doi.org/10.1007/s12555-017-0117-z.

[7] Chi Zhang, King Jet Tseng, ( 2013), "Design and control of a novel flywheel energy storage system assisted by hybrid mechanical-magnetic bearings“, Mechatronics, Vol. 23 (3), pp. 297 309, ISSN 0957-4158, https://doi.org/10.1016/j.mechatronics.2013.01. $\underline{008}$.

[8] Arai, Y.; Seino, H.; Yoshizawa, K.; Nagashima, K. "Development of superconducting magnetic bearing with superconducting coil and bulk superconductor for flywheel energy storage system" http://adsabs.harvard.edu/abstract_service.html,
2013.

[9] M. Ghanaatian and S. Lotfifard, (2019) "Control of Flywheel Energy Storage Systems in the Presence of Uncertainties," in IEEE Transactions on Sustainable Energy, Vol. 10 (1), pp. 36-45, Jan. 2019, DOI: 10.1109/TSTE.2018.2822281.

[10] B. Abdi, A. Alimardani, R. Ghasemi, and S. M. M. Mirtalaei. (2013), "Energy Storage Selection for LEO Satellites, International Journal of machine learning \& computing“, IJMLC 2013. Vol.3 (3): 287-290 ISSN: 20103700, DOI: 10.7763/IJMLC.2013.V3.322.

[11] T. Elsayed, T. A. Youssef, Student Members, IEEE, and O. A. Mohammed, Fellow, IEEE "Modeling and Control of a Low Speed Flywheel Driving System for Pulsed Load Mitigation in DC Distribution Networks" IEEE Transactions on Industry Applications, Vol. 52 (, Issue: 4, July-Aug. 2016.

[12] Mustafa E. Amiryar and Keith R. Pullen "A Review of Flywheel Energy Storage System Technologies and Their Applications" ,pp 266286 ,16 March 2017 applied sciences journal.

[13] Akhil, A.A.; Huff, G.; Currier, A.B.; Kaun, B.C.; Rastler, D.M.; Chen, S.B.; Cotter, A.L.; Bradshaw, D.T.; Gauntlett, W.D. DOE/EPRI 2013, "Electricity Storage Handbook in Collaboration with NRECA“" U.S. Department of Energy: Oak Ridge, TN, USA, 2013.

[14] Li, Xiaojun; Anvari, Bahareh; Palazzolo, Alan; Wang, Zhiyang; Toliyat, Hamid (2018), “A Utility-Scale Flywheel Energy Storage System with a Shaftless“, Hubless, High-Strength Steel Rotor". IEEE Transactions on Industrial Electronics. (2018), Vol. 65 (8): 6667-6675.

DOI:10.1109/TIE.2017.2772205. ISSN 0278-0046.

[15] Donald Rapp, Tom Hamilton, "Solar Cell and Array Technology for Future Space Science Missions". California institute of technology Pasadena, California, pp. 8, 2002.

[16] Martin A. Green, Yoshihiro Hishikawa, Ewan D. Dunlop, Dean H. Levi, Jochen HohlEbinger, Masahiro Yoshita, Anita W.Y. HoBaillie "Solar cell efficiency tables (Version 53)”, pp 3-12, 25 December 2018.

[17] Ahmed lofty, Wagdy R Ains, M. A. Atalla, Joseph V. M. Halim and M. Abouelatta "Design an optimum PV system for the satellite Technology using High Efficiency Solar Cell" International Journal of Computer Application, pp 0975 - 8887 , Vol. 3, 2017.

[18] Safta batteries. [Online]. Available: http://www.saftbatteris.com, 2020.

[19] PDF, EPub, Mobi, Kindle online, "Free book 
Elements Of Spacecraft Design“, (Aiaa Education Series) by Charles D. Brown, 2021.

[20] Samosir, A. S., Gusmedi, H., Purwiyanti, S., \& Komalasari, E., "Modeling and Simulation of Fuzzy Logic based Maximum Power Point Tracking (MPPT) for PV Application", International Journal of Electrical and Computer Engineering (IJECE), (2018), 8(3) : 1315-1323.

[21] Rath, B. B., Kishore, T., Ramana, P. V., Prasad, P. R., \& Saheb, S. P., "A Fuzzy Logic Control Based Maximum Power Point Tracker for a Stand Alone Solar Photovoltaic System under Uniform Radiation Condition". International Journal of Multidisciplinary Research (IJMR), .209-202 pp :5، (2019)

[22] Lee, J., Kim, E., \& Shin, K. (2013). "Design and Management of Satellite Power Systems", 2013 IEEE $34^{\text {th }}$ Real-Time Systems Symposium, pp 97-106.

[23] https://www.cgsatellite.com/satellite-componentflywheel/\#contact

\section{Appendix}

The used flywheel main technical indicators [23]

\begin{tabular}{|c|c|}
\hline \multicolumn{2}{|c|}{ Technical Specifications } \\
\hline emsI & Specifications \\
\hline Operating mode & Counteraction \\
\hline output Rated & $\leq 50 \mathrm{~m}$. N.m \\
\hline $\begin{array}{c}\text { Rated angular } \\
\text { momentum }\end{array}$ & (Rated velocity:6000rpm) \\
\hline Rated speed & $(600 \mathrm{rpm} @) \mathrm{Nm} \cdot \mathrm{s} 2$ \\
\hline Speed control accuracy & $4800 \mathrm{rpm}$ \\
\hline Control pattern & speed $\geq 1000 \mathrm{rpm}( \pm 1 \mathrm{rpm})$ \\
\hline Output interface & Speed control $/ \mathrm{Torque}$ control \\
\hline Supply voltage & $\mathrm{RS} 422 / \mathrm{CAN}$ \\
\hline $\begin{array}{c}\text { Power consumption } \\
\text { under static state }\end{array}$ & $\mathrm{V} 28$ \\
\hline $\begin{array}{c}\text { Power consumption } \\
\text { under steady state }\end{array}$ & $\leq 3 \mathrm{~W}$ \\
\hline Peak power consumption & $(\mathrm{rpm} 6000 @) \leq 10 \mathrm{~W}$ \\
\hline Environment suitability & $\leq 70 \mathrm{~W}$ \\
\hline $\begin{array}{c}\text { External envelope } \\
\text { dimension }\end{array}$ & ${ }^{\circ} \mathrm{C} 45+\sim{ }^{\circ} \mathrm{C} 10-\mathrm{Temperature:}$ \\
\hline Weight & $160 \mathrm{~mm} \times 160 \mathrm{~mm} \times 160 \mathrm{~mm}$ \\
\hline Homologous products & $\mathrm{kg} \pm 0.5 \mathrm{~kg} 3$ \\
\hline $\begin{array}{c}\text { Delivery cycle } \\
\mathrm{ms} / 2 \mathrm{Nms} / 5 \mathrm{NmsN} 1\end{array}$ \\
\hline
\end{tabular}

